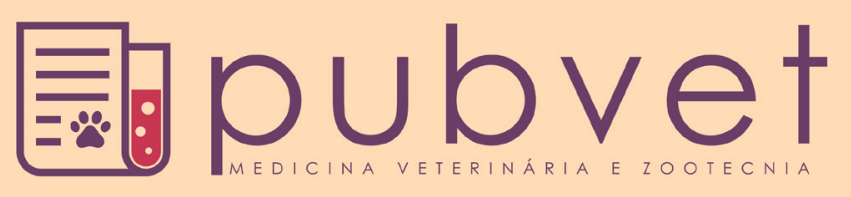

HTTP://DX.DOI.ORG/10.22256/PUBVET.V11N8.771-774

\title{
Carcinoma de células basais em cadela: Relato de caso
}

\section{Nhirneyla Marques Rodrigues ${ }^{1 *}$, Sávio Soares Barbosa Dantas ${ }^{2}$, Ana Maria Quessada ${ }^{3}$, Daniel Serafim de Andrade Rodrigues ${ }^{4}$}

${ }^{1}$ Mestre em Ciência Animal da Universidade Federal do Piauí, Teresina, Piauí, Brasil-nhirnevla@hotmail.com

${ }^{2}$ Residente Multiprofissional em Medicina Veterinária - Área: Patologia Clínica. Universidade Federal do Piaui - Teresina, Piauí, Brasil savioveterinario@hotmail.com

${ }^{3}$ Professora de Mestrado e Doutorado em Ciência Animal da UNIPAR - Umuarama, Paraná, Brasil-quessadavet@gmail.com

${ }^{4}$ Acadêmico de Medicina Veterinária, Universidade Federal do Piauí - Teresina, Piauí, Brasil-danielserafimvet@gmail.com

*Autor para correspondência

RESUMO. A Oncologia Veterinária tem tido muita demanda, especialmente pelo aumento da longevidade dos cães e pela maior ocorrência de neoplasias em animais idosos. Foi atendida uma cadela, sem raça definida, 8 anos, apresentando massa tumoral ulcerada na região frontal da cabeça. Esta foi submetida a exames pré-operatórios. Em seguida, a exérese do tumor com ampla margem de segurança. Foi realizado exame histopatológico dos fragmentos tumorais coletados, diagnosticando-o como carcinoma de células basais.

Palavras chave: canino, cirurgia, neoplasia, oncologia

\section{Basal cell carcinoma in bitch: Case report}

ABSTRACT. Veterinary Oncology has been in great demand, especially for the increase in the longevity of dogs and the greater occurrence of neoplasias in elderly animals. A bitch, without breed, was treated for 8 years, presenting an ulcerated tumor mass in the frontal region of the head. The patient underwent preoperative exams. Then, the tumor is excised with a large margin of safety. Histopathological examination of the collected tumor fragments was performed, diagnosing it as basal cell carcinoma.

Keywords: Canine, surgery, neoplasia, oncology

\section{El carcinoma de células basales en un perro: Reporte de un caso}

RESUMEN. La Oncología Veterinaria ha tenido mucha demanda, en especial mediante el aumento de la longevidad de los perros y la mayor incidencia de cánceres en animales más viejos. Fue atendida una hembra canina mestiza, edad de ocho años, presentando una masa tumoral ulcerada en la región frontal de la cabeza. Esta fue sometida a exámenes preoperatorios. A continuación, la resección del tumor con amplia margen de seguridad. De los fragmentos del tumor colectados se realizó examen histopatológico, diagnosticándolo como carcinoma de células basales.

Palabras clave: Cáncer, canino, cirugía, cáncer, oncología

\section{Introdução}

A Oncologia Veterinária vem despontando nos últimos anos, isso se deve, entre muitos fatores, pelo aumento da longevidade de cães, maiores cuidados e promoção de bem-estar por parte dos tutores (Bagliotti et al., 2015) e pelo fato do câncer ser uma das principais causas de óbito (Bentubo et al., 2007). As neoplasias ocorrem independentes da idade, mas como se espera, tem maior índice nos cães idosos (Borges et al., 2016).

Não diferente do humano, esta doença causa grande impacto psicológico em seus tutores, por associarem o câncer ao sofrimento, dor e óbito (Costa et al., 2016), o que pode gerar medo ou 
dificuldade no tratamento, exigindo do Médico Veterinário habilidade e prática para orientar bem as condutas a serem realizadas.

Dentre as neoplasias em cães, as de pele tem grande frequência e em alguns estudos só aparecem menos frequentes que os tumores de mama (Felisberto et al., 2015, De Nardi et al., 2002). Podem ser benignos ou malignos, acometem comumente fêmeas e machos e diversas raças (Fernandes et al., 2015). São citadas como neoplasias cutâneas: melanoma, mastocitoma, carcinoma de células escamosas, carcinoma de células basais, lipoma, papiloma, dentre outras (Souza et al., 2006).

Dentre as várias modalidades de carcinomas, os de células basais, não são tão frequentes, possuem baixo grau de malignidade, ocorrendo em sua maioria isoladamente de outras lesões, mas podendo às vezes haver infiltração na derme profunda (Blanca et al., 2016).

$\mathrm{O}$ diagnóstico pode ser obtido por citologia aspirativa por agulha fina (CAAF), de modo rápido e pouco invasivo, indicando características de malignidade ou não (Braz et al., 2016). Todavia, a histologia é tida como padrão ouro, além de determinar se as margens removidas estão livres de células neoplásicas (Sá, 2014). A exérese cirúrgica é o tratamento de escolha (Blanca et al., 2016).

O objetivo deste trabalho foi relatar um caso de neoplasia de células basais na cabeça de um canino e o tratamento realizado.

\section{Relato de caso}

Foi atendida em um Hospital Universitário, uma cadela, sem raça definida (SRD), de oito anos, não castrada, apresentando nodulação ulcerada na parte frontal da cabeça (Figura 1). O tutor da mesma relatou que o animal o apresentava há aproximadamente 1 ano, chegando a ulcerar. O animal não se queixava de dor ou desconforto, porém havia secreção serosa desagradável e atingia aproximadamente seis centímetros $(\mathrm{cm})$. Possuía o histórico de vermifugação e vacinas atualizadas. Sua alimentação era baseada exclusivamente em comida caseira. Ao exame clínico, notou-se a paciente em estado corporal magro, com mucosas oral e ocular hipocoradas, leve desidratação, linfonodos palpáveis aumentados de volume, não havia presença de ectoparasitas, auscultação e pulso sem anormalidades e sem alterações aparentes nos demais aparelhos e órgãos.

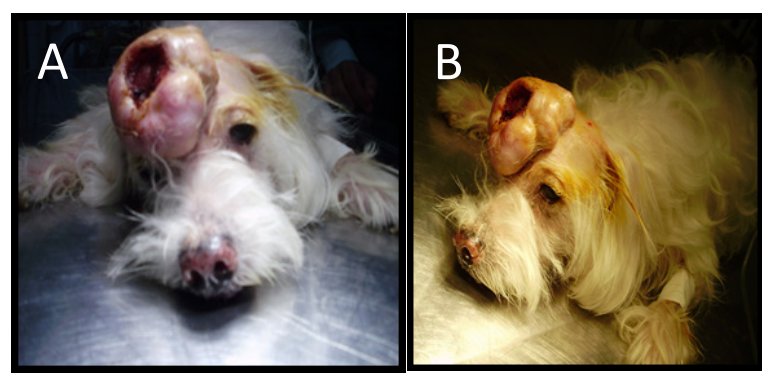

Figura 1. Canino fêmea, 8 anos, sem raça definida, possuindo neoplasia (carcinoma de células basais) na região frontal do crânio. A - Vista frontal, B - Vista lateral.

Foram solicitados exames complementares para avaliação pré-cirúrgica (hematológico, citologia da nodulação, exames cardiológicos, radiografias do crânio e tórax e posteriormente histopatológico), que revelaram: leve anemia e trombocitopenia, bioquímicos sem alterações, assim como exames cardiológicos e do crânio e tórax, demonstrando apenas a massa na região frontal da cabeça, mas sem comprometimento dos ossos craniais ou presença de metástase. Quanto ao exame citológico, notou-se presença de células epiteliais (aglomerados-agrupamento caseoso), presença de células mesenquimais (soltas), compatível com Carcinoma de células basais e sem características de malignidade até o momento do exame.

A paciente foi internada para o preparo cirúrgico recebendo previamente à cirurgia analgesia (tramadol $3 \mathrm{mg} / \mathrm{kg}$, via intramuscular e meloxicam $0,2 \mathrm{mg} / \mathrm{kg}$, via subcutânea) e antibioticoterapia (Cefalotina $30 \mathrm{mg} / \mathrm{kg}$, via endovenosa). Realizou indução com diazepan $(0,5 \mathrm{mg} / \mathrm{kg}$, via endovenosa) e propofol ( $3 \mathrm{mg} / \mathrm{kg}$, via endovenosa). Manutenção com anestésico inalatório: isoflurano em circuito semi-aberto.

Realizou-se uma ampla extirpação cirúrgica da neoplasia (Figura 2), conforme indica a literatura, sem muitas complicações, já que a massa não se encontrava infiltrada da derme ou musculatura. Houve plastia da área, com retirada da pele flácida em excesso. Suturou-se o tecido subcutâneo com fio absorvível (vicryl 3.0) e pele com fio não absorvível (mononylon 3.0) em pontos simples separados. A neoplasia removida (Figura 3) foi seccionada e encaminhada para realização de exame histopatológico, diagnosticando com carcinoma de células basais.

O animal ficou em observação pós-cirúrgica, estando de alta 24 horas após. Recomendou-se o uso de colar protetor, analgesia e antibioticoterapia já iniciada na internação, com remoção dos pontos após 10 dias de cicatrização. 
Atualmente, após contato com o proprietário, o mesmo informou que o animal vive bem.

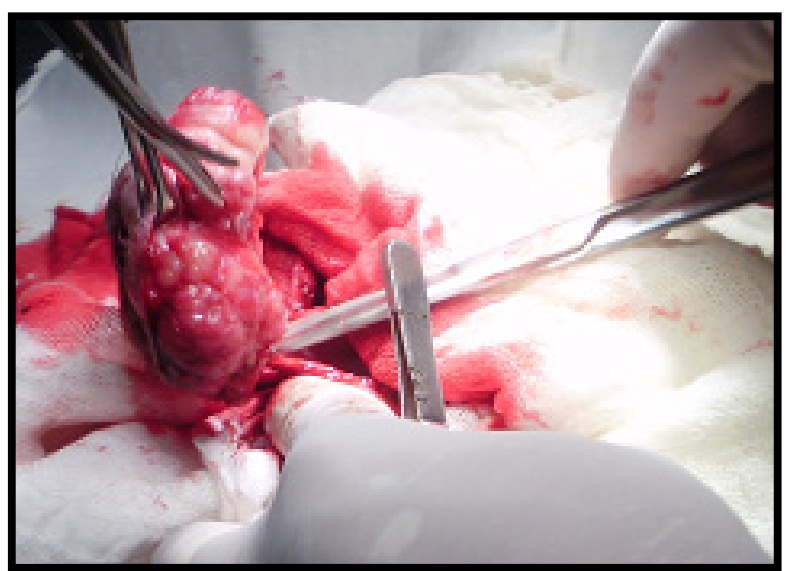

Figura 2. Canino fềmea, 8 anos, sem raça definida, sendo submetida à exérese do tumor (carcinoma de células basais) localizado na cabeça.

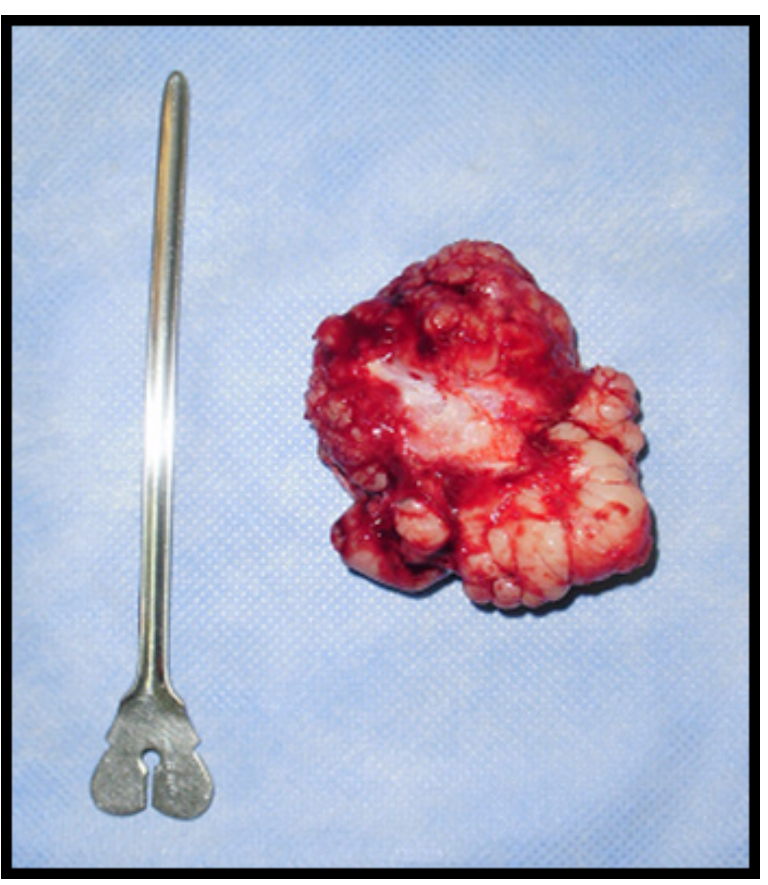

Figura 3. Tumor (carcinoma de células basais) removido de canino fêmea, 8 anos, sem raça definida, localizado na cabeça. Aspecto firme.

\section{Resultados e Discussão}

A oncologia é uma área da Medicina Veterinária que tem tido grande demanda, especialmente quando relativa a tumores cutâneos, por apresentarem um número elevado de ocorrências e pelo fato de ser uma lesão facilmente detectada pelo tutor de cães (Souza et al., 2006). Isto se mostra bem evidente neste caso relatado, uma vez que a neoplasia mostrou-se bem delimitada.

O local de ocorrência do tumor, a cabeça, está entre os locais mais acometidos, juntamente ao pescoço e parte cranial do tronco segundo a literatura (Blanca et al., 2016). Notou-se anemia de grau leve na cadela em questão, permitindo a remoção cirúrgica sem que fosse necessária a realização de transfusão sanguínea. Isso se deve ao fato de alguns pacientes neoplásicos, possuírem anemia em virtude de doença crônica e suas perdas. Justifica-se tal fato por conta da redução da sobrevida da hemácia, falhas na medula óssea na tentativa de aumentar a produção e distúrbios na mobilização do ferro (Cançado and Chiattone, 2002). Além de, quando ulcerados, como no caso relatado, perdas crônicas de sangue contribuem para a ocorrência de anemia.

Diferente de outros tipos de carcinomas, os de células basais têm menor caráter de malignidade, geralmente alopécicos, solitários, proeminentes e bem delimitados; condizendo com as características tumorais da cadela em questão (Blanca et al., 2016)). Por estas características se atribui a baixa ocorrência de metástase em outros locais.

Ao exame citológico do tumor, notou-se presença de células epiteliais (aglomeradosagrupamento caseoso), presença de células mesenquimais (soltas), onde até o momento do exame, não havia critérios de malignidades presentes, direcionando a sua remoção, como indica a literatura (Blanca et al., 2016). Sabe-se que o exame histopatológico confirma a etiologia do tumor (Borges et al., 2016), tendo o mesmo diagnosticado carcinoma de células basais.

Conforme o tipo de tumor, diferentes modalidades de tratamentos podem ser aplicadas, a saber: cirurgia (De Nardi et al., 2002), quimioterapia (Bagliotti et al., 2015) ou ambas concomitantemente (De Nardi et al., 2002). Todavia, nos casos de carcinoma de células escamosas, a exérese cirúrgica é o tratamento de escolha (Blanca et al., 2016), não havendo necessidade de realização de quimioterapia, uma vez que o tumor foi retirado respeitando uma boa margem de segurança e é o que se preconiza em cirurgias oncológicas (Sá, 2014).

Relatos deste tipo contribuem com a literatura, que ainda é um pouco escassa para este tipo de tumor especificamente. E quanto à casuística, não são tão frequentes (Souza et al., 2006).

\section{Conclusão}

Há um grande número de casos de neoplasias em cães, exigindo habilidade e conhecimento por parte do Médico Veterinário. O carcinoma de 
células basais é uma neoplasia cutânea de baixa incidência e malignidade, que se não muito infiltrada, tem como a exérese cirúrgica o seu tratamento de escolha.

\section{Referências Bibliográficas}

Bagliotti, C., Gomes, M., OlivioO, M., Santilli, J. \& Calazans, S. 2015. Levantamento dos casos de quimioterapia no Hospital Veterinário da Unifran no período de um ano. Investigação, $14,951$.

Bentubo, H. D. L., Tomaz, M. A., Bondan, E. F. \& Lallo, M. A. 2007. Expectativa de vida e causas de morte em cães na área metropolitana de São Paulo (Brasil). Ciência Rural, 37, 10211026.

Blanca, W. T., Coleto, A. F., Gundim, L. F., Souza, R. R., Barros Bandarra, M., Medeiros, A. A. \& Almeida Moreira, T. 2016. Carcinoma de células basais em orelha de cão-relato de caso. Veterinária Notícias, 20, 23-23.

Borges, I. L., Silva Ferreira, J., Matos, M. G., Pimentel, S. P., Lopes, C. E. B., Araújo, V. D. \& Sousa, F. C. 2016. Diagnóstico citopatológico de lesões palpáveis de pele e partes moles em cães. Revista Brasileira de Higiene e Sanidade Animal, 10, 382-395.

Braz, P. H., Brum, K. B., Souza, A. I. \& Abdo, M. A. 2016. Comparação entre a citopatologia por biopsia com agulha fina e a histopatologia no diagnóstico das neoplasias cutâneas e subcutâneas de cães. Pesquisa Veterinária Brasileira, 36, 197-203.

Cançado, R. D. \& Chiattone, C. S. 2002. Anemia de doença crônica. Revista Brasileira de Hematologia e Hemoterapia, 24, 127-36.

Costa, M. L., Carvalho, L. L., Stupak, E. C., Mariani, O. M., Barros, J. C., A., A. N., R., N. M. \& Calazans, S. G. 2016. O conceito de câncer na perspectiva de tutores de cães e gatos. Investigação, 15, 951.
De Nardi, A. B., Rodaski, S., Sousa, R. S., Costa, T. A., Macedo, T. R., Rodigheri, S. M., Rios, A. \& Piekarz, C. H. 2002. Prevalência de neoplasias e modalidades de tratamentos em cães, atendidos no hospital veterinário da Universidade Federal do Paraná. Archives of Veterinary Science, 7, 15-26.

Felisberto, Â. C. T., Carvalho, G. D., Favarato, E. S. \& Silva, A. S. A. 2015. Casuística de cães atendidos com suspeita de neoplasia no Hospital Veterinário da Univiçosa, no período de 2007 a 2009DE 2007 A 2009. Revista Simpac, 2, 177-182.

Fernandes, C. C., Medeiros, A. A., Magalhães, G. M., Szabó, M. P. J., Queiroz, R. P., Silva, M. V. A. \& Soares, N. P. 2015. Frequência de neoplasias cutâneas em cães atendidos no hospital veterinário da Universidade Federal de Uberlândia durante os anos 2000 a 2010. Bioscience Journal, 31, 541-548.

Sá, S. V. G. 2014. Análise citológica vs histopatológica no diagnóstico de tumores de canídeos. Medicina Veterinária. Universidade de Trás-os-Montes e Alto Douro, Vila Real.

Souza, T. M., Fighera, R. A., Irigoyen, L. F. \& Barros, C. S. L. 2006. Estudo retrospectivo de 761 tumores cutâneos em cães. Ciência Rural, $36,555-560$.

\section{Article History:}

Received 15 April 2017

Accepted 19 May 2017

Available on line 20 June 2017

License information: This is an open-access article distributed under the terms of the Creative Commons Attribution License 4.0, which permits unrestricted use, distribution, and reproduction in any medium, provided the original work is properly cited. 